\title{
Barriers to Accessing Services by People with Disabilities in Nigeria: Insights from a Qualitative Study
}

\author{
C. Jonah Eleweke, Ph.D \\ Department of World Languages and Literatures, Portland State University \\ Portland, Oregon, OR 97201; Email: jeleweke@pdx.edu \\ Jannine Ebenso, MA \\ The Leprosy Mission International, 80 Windmill Road, Brentford, Middlesex \\ TW8 0QH, England, UK; Email: janninee@tImint.org
}

Doi:10.5901/jesr.2016.v6n2p113

\section{Abstract}

\begin{abstract}
This article examines the experiences of people with disabilities in Nigeria and specifically the barriers they encounter in accessing various services in the country based on the framework of the social model of disability. Qualitative methods were utilized in the data collection and interpretation. The results indicated that people with disabilities in the country encounter a plethora of barriers in accessing various important services. These obstacles to accessing essential services deprive people with disabilities the opportunity to acquire services that would enhance the development of their potential and leading productive and contributing lives. These barriers to accessing services and the implications of strategies that could ameliorate these adverse conditions are discussed.
\end{abstract}

Keywords: Nigeria, people with disabilities, barriers to accessing services.

\section{Background and Overview of Disabilities in Nigeria}

Nigeria, a country in West Africa, is the most populous nation of Black people in the world with an estimated population of over 150 million people (Index Mundi, 2011). The World Health Organization and the World Bank Report on Disability (2011) estimated that fifteen percent of the world's population, over one billion, are people with disabilities. It is estimated that 80 percent of these people live in developing countries including Nigeria (United Nations, 2010). It is estimated that Nigeria has more than 22 million citizens with disabilities because a valid census of these people has not been conducted since after independence from Britain in 1960 (Eleweke, 2013; Obiakor \& Eleweke, 2014). This high estimate of disabilities in the country is because preventable illnesses and diseases that can cause disabilities are still endemic in Nigeria. There is inadequate immunization coverage in the country resulting in the continued presence of many preventable diseases that can result in disabilities (Department for International Development, 2000). Poor maternal and neo-natal care also contribute to significant numbers of disabilities in infants in the country (Smith, 2007). Further, Smith observed that poor trauma care at the health facilities in the country resulted in infections causing further disabilities. Evidence indicates that the majority of people with disabilities in the country might be unable to access services due to a litany of barriers. Data from Smith (2011) study indicated that half of the participants had never attended schools. Only nineteen percent completed primary school and only eight percent completed secondary school. This limited education in Smith's sample was associated with a very high rate of unemployment among people with disabilities in the country.

Nigeria ratified the UN Convention on the Rights of People with Disabilities (CRPD) on 24th September 2010 (UN, 2011a, b), and hosted the Africa Regional Community-Based Rehabilitation (CBR) conference on October 7, 2010 (CBR Africa Network [CAN], 2011). These two important events placed disability issues on the agenda in Nigeria for policymakers and civil society. Nonetheless, evidence indicates that people with disabilities in the country continue to experience discrimination, exclusion, and encounter barriers in accessing various services in the country (Eleweke, 2013; Obiakor \& Eleweke, 2014). Implementation of the articles in the UN Convention and other such documents ratified by the Nigerian government has remained at the theoretical level because the government has not enacted a legislation to provide the legal framework for implementation (Eleweke, 2013; Obiakor \& Eleweke, 2014). Although in 1993, the military government of General Sani Abacha published the Nigerians with Disability Decree (Disability Rights Education and 
Defense Fund, 2011), there was no evidence that the decree was ever implemented by successive governments. In March 2009, the Nigerian Senate approved a Disability Bill. The bill prohibits all forms of discrimination against people with disabilities. Further, the bill demands equal opportunities in all aspects of life for individuals with disabilities. It stipulated that all public buildings should be accessible to people with disabilities. It included punitive actions for corporate bodies and individuals found discriminating against people with disabilities (Adelaja, 2009; Ogala, 2009). However, the bill has not been signed into law by the president (Eleweke, 2013).

This study emanated from questions put to one of the authors at the CBR conference by some Nigerians with disabilities desiring improvements in their abilities to access services that would enhance the development of their potential so that they could live productively. There is not, to our knowledge, a study that has provided people with disabilities in Nigeria the opportunity to express their views on the obstacles they encounter in accessing various services in the country. This study therefore aimed at giving an opportunity to Nigerians with disabilities to express their opinions on their experience of discrimination, exclusion, and barriers to accessing services in the country. Data from this study would yield important insights and provide a platform for people with disabilities in the country in their advocacy for better treatment and access to services.

\section{Study Framework}

This study utilized the social model of disability, which considers that "disability is a social creation" (Barnes, 1992, p. 118). This model perceives disabilities as the consequences of social exclusion, discrimination, and barriers to accessing services rather than problems of individual bodily functions per se. In contrast to the medical deficit or individual model, which focuses on individual impairments and functional limitations, the social model considers disability to be a form of social oppression or exclusion experienced collectively by people with disabilities (Barnes \& Mercer, 2004; Oliver, 1990, 2004). In other words, the consequences of bodily impairments are exacerbated by the social oppression, exclusion, and barriers in accessing services that people encounter (Shakespeare \& Watson, 2002). The social model has been a significant platform in the struggle to guarantee the fundamental human rights of people with disabilities in the United Kingdom, United States, Canada, and many other developed countries. It is considered a practical tool for explaining and exploring issues about exclusion, disadvantage, and discrimination experienced by people with disabilities (Oliver, 2004). The social model of disability has been important in our understanding of the systematic oppression of people with disabilities by the non-disabled majority in the society and societal institutions. As the Union of the Physically Impaired Against Segregation (UPIAS, 1976, p. 3) earlier argued: "Disability is something imposed on top of our impairments by the way we are unnecessarily isolated and excluded from full participation in society". Thus, this study focused on the social, cultural, and environmental barriers people with disabilities in Nigeria might encounter, which hinder their access to services, development of their potentials, and contribution to national and global developments. The main aim of this study, therefore, was to identify the disabling barriers (evident in policies, systems, and services) that excluded people with disabilities in Nigeria by gathering data from some of them. In order to achieve this goal in the context of the social model of disability, this study was designed to provide an opportunity for Nigerians with disabilities to express their views on the various disabling barriers they encountered in their attempt to access various services. Consequently, data were collected from representatives of disabled people's organization (DPOs) and some individuals with disabilities in the country via e-mailed questionnaires and telephone interviews.

\section{Data Gathering and Analysis}

Qualitative methods were utilized in the gathering and analyzing data. The social model of disability was the framework for this study. It was therefore imperative that people with disabilities in the country were provided the medium to express their views on the disabling barriers they encountered in their attempt to access services. E-mailed questionnaires and telephone interviews were utilized in gathering data from 5 executives of DPOs and 7 individuals with disabilities in the country. In the context of the social model of disability, which suggests that people with disabilities are in the best position to describe their obstacles to accessing services, this study was conducted 'with' and not 'on' people with disabilities (Swain \& French, 2004). Consequently, data were generated by the accounts of disabling barriers provided by people with disabilities.

The DPOs officials and individuals that participated in this study were identified through contact with the umbrella national organization for people with disabilities in the country. Individuals involved with managing DPOs in the country tended to be those people with disabilities with good college education and at least obtained bachelor's degrees in the 
country. Through their experiences growing up in the country and attending schools, they had wealth of information and experiences about the disabling barriers in the country that people with disabilities must navigate in attempting to access various services. It was therefore fitting that they were involved in this study. Nonetheless, effort was made to obtain broader perspectives from people with disabilities who were not officials of DPOs. Given that all those involved with managing DPOs were in the urban centers, some people with disabilities living in semi-urban areas were purposively identified and interviewed by telephone. Further, the participants were individuals with different disabilities. Thus, the narratives of their experiences of various disabling obstacles they encountered in accessing services further provided richer insights.

After pilot-testing and necessary modifications were made to the questionnaires, they were sent via e-mail to the executives of the DPOs who had replied to an earlier email soliciting participation. The questionnaire had two parts. The first part sought basic information about the disability organizations. The second part comprised open-ended questions about experiences of disability and people with disabilities in the country in accessing various services. The questionnaires were accompanied by informed consent form and a cover letter. The letter explained the purpose and importance of this study. The participants were assured of anonymity and confidentiality of information they provided and their cooperation in completing the questionnaires was solicited. It was anticipated that by electronically administering the questionnaire, responses would be obtained from more DPOs across the country. Nonetheless, after the initial e-mailing of the questionnaire to the 23 DPOs that indicated willingness to participate in the study and repeated weekly emailings, only five of these DPOs returned completed questionnaires within the time frame provided. A secure server was used for the purpose of sending and receiving the questionnaires. Completed questionnaires received were securely stored.

Seven individuals (four females and three male, ages $37-52$ years) with disabilities were purposively selected and interviewed via telephone. This was to gain a deeper understanding of the experiences of people with disabilities in the country regarding societal barriers to accessing services. The interviews were conducted following a written guide to avoid biases and enhance objectivity. Open-ended questions were utilized to enable the interviewees provide as much or as little information as comfortable to them. Nonetheless, based on some responses, some spontaneous follow up questions were asked to obtain richer understanding of the responses. The interviews were audio-recorded and fully transcribed later. Each transcript was sent to the interviewees to check for accuracy.

A limitation to the data collection was the few people with disabilities that participated in this study. Nonetheless, these people had different disabilities and experiences. Combined, the interviewee responses and information from questionnaires provided rich insights into disabling barriers in the country. Despite the small sample size, the disabling barriers in the society were recurring themes in the responses provided by the participants. This provided consistency and reliability to the data described below.

\section{Results}

Thematic procedures were utilized in analyzing the questionnaire and interview data. Reading through the vast amount of data, common themes (open-coding) and in some cases relationships between the themes (axial-coding) were established. These procedures are essential features of qualitative data analyses (Blaikie, 2000; Charmaz, 2001; Creswell, 2012). The primary analyses were shared with the participants to check for accuracy and clarity of their statements. The important themes generated from the data are discussed below.

\subsection{Implementation of Policies and Disability Legislation}

The participants were unanimous in stating that Nigeria's endorsement of various United Nations 'Declarations on the Rights of the Disabled', and in particular the ratification of the Convention on the Rights of Persons with Disabilities were encouraging developments. They stated that these developments provided DPOs and people with disabilities in the country greater opportunities to discuss disability issues with policy-makers. Nonetheless, they stressed that evidence of implementation of the provisions in the policies were lacking. According to these participants, the government had not taken actions to implementing the policies. They stated that people with disabilities in the country were not treated as full citizens with fundamental human rights. As one interviewee stated:

Any person with a physical disability or any deformity in Nigeria is treated like a dog depending on where he (sic) comes from. Some may not regard a physically challenged person as a human being.

A recurring theme from the participants was that it remained very challenging for them to access services due to 
the absence of enabling policies and laws. Consequently, they stated that they encountered many disabling barriers in attempting to access various services. One of the participants expressed the view that people with disabilities in the country were "..swimming against the tide.." in attempting to access services because of the absence of any legal framework for implementing policies such as the UN Convention that the government ratified.

While the UN Convention and other relevant policies have provided impetus to disability movement in the country in their agitation for positive changes and access to services, it remains the case that over a decade had been spent trying to ensure the enactment of a national anti-discriminatory legislation specifically relating to disability. On a positive note, two participating DPOs managers reported that 4 of the 36 states in the country - Plateau, Ekiti, Lagos, and Bauchi had enacted disability laws that aimed at removing discrimination and obstacles to accessing services by individuals with disabilities in these states. Nonetheless, the participants lamented the absence of a national anti-discriminatory legislation in Nigeria. They asserted that the absence of such a law remained one of the biggest obstacles to ensuring people with disabilities were recognized as equal citizens and their rights to access services upheld. They expressed the view that a national disability legislation that is effectively implemented would be the single biggest catalyst to combating disabling barriers in Nigeria.

\subsection{Roles of Disabled People's Organizations (DPOs)}

The participants stressed the important roles of DPOs in the struggle to promote public awareness of the needs of people with disabilities and exerting pressure on the government to enact and implement enabling laws that would lead to eliminating discrimination and removing disabling barriers. According to one of the participants, DPOs were important in order "...to get the voice of members heard loud and clear - through advocacy and awareness strategies". Another participant added that DPOs were, "...supposed to promote disabled rights ....so that they will feel accepted in the society and in everything". However, most of the participants expressed disappointments in the work of most DPOs in the country. According to one participant: "Most DPOs have become charity/welfare organizations where their leaders would rather focus on getting immediate [financial] gratification". Another participant stated that:

The few DPOs that do exist in the northern parts of the country are run (sic) by a few people who have access to the government [contracts]. They accumulate money and other benefits for themselves......but they don't do any advocacy...

These comments suggested that the executives of DPOs might be working for their personal benefits rather than ensuring the disabling barriers people with disabilities encountered in accessing services were brought to the attention of the policy-makers and the government pressured to enact and implement laws that could result in improvements.

\subsection{Physical Access to Programs and Services}

The DPOs managers unanimously stated that structural and physical barriers to accessing programs and services adversely affected all aspects of the lives of people with disabilities in the country. Places of business, healthcare, education, employment, transport, recreation, sport and leisure, and the justice system have major structural barriers, which prevented people with disabilities from accessing programs and services provided by these entities. It was very clear from their comments that people with disabilities in the country encountered physical barriers in accessing public buildings. All the participants who used mobility aids (including guide canes or wheelchairs) reported physical barriers which restricted their access to programs and services. They lamented that buildings in Nigeria were not "disability friendly". For instance, due to increasing insecurity in the country, banks in the major cities changed their public entrances to narrow security cages barely large enough for a standing adult to squeeze through. According to one of the DPOs officials, access into these banks is impossible for people using walking aids or wheelchairs. One of the interviewees traveled around country regularly and needed to stay in hotels. This invariably caused problems as the participant stated:

Hotels in Nigeria are not accessible [to individuals with mobility disabilities]. The only one is maybe B...(full name provided) in Abuja, but it is expensive. Even there I have to remove the side of the wheelchair to enter the bathroom. But then the other hotels are even worse, I cannot even enter the hotel room [with my wheelchair].

Accessibility was not just a problem for those using wheelchairs or walking aids, but also for people with visual impairments. A blind participant stated: "Considering the kind of environment we live in with physical obstacles 
everywhere, mobility is one area that blind people have a problem [in attempting to access program and services]".

Clearly, inaccessibility of buildings denied people with disabilities their rights to access services in the country. In addition, according to the accounts of the participants, equipment, for instance, in healthcare centers might not be suitable for wheelchair users. According to one of the participating DPOs officials, the examination tables in healthcare centers could not be lowered or otherwise manipulated for the transfer of wheelchair users for examination. Staff in the such centers might have to physically transfer the wheelchair user to the examination table. The participants considered this to be dehumanizing and uncomfortable.

Further, some of the participants mentioned other physical access issues encountered by workers with disabilities in the workplace. Interestingly, not all experiences were negative. One participant described how her employers provided an accessible workplace environment following her employment: "I was fortunate that the office was built after I arrived there, so they thought about things like ramps. My executive chairman made a ramp to my office and then also to the conference room."

Other accounts were not so positive, however. Most of the participants reported the existence of structural and physical barriers they encountered daily at work and other places of service. These included the lack of ramps, lack of lifts, narrow entrances and corridors, inaccessible restrooms, and tight, over-crowded offices.

\subsection{Employment}

In many developing countries such as Nigeria social protection or benefits for poor and people with disabilities may be lacking. Consequently, employment is very essential for earning regular income. Six of the 7 interviewees indicated they were working full time. The participants had college education. The participants stated that one of the reasons educated people with disabilities could have a hard time finding jobs was people's negative attitudes toward those with disabilities. They reported varied experiences regarding barriers in the workplace and attitudes of their colleagues without disabilities. It was clear from their accounts that the attitude of their colleagues made significant impacts on their job performances. There were accounts of work colleagues helping when needed. According to one of the interviewees:

I did not encounter any difficulties as a deaf person because of the kind of boss I had. She was very open-minded. Any information she needed me to know, she took the pains to write it for me.

Another participant stated:

When I come [to work] I park my car. Someone [co-workers] will remove my wheelchair from the booth and then wheel me into the office. I was fortunate that the office was built after I arrived there, so they thought about things like ramps.

These accounts of efforts made by employers and colleagues to accommodate workers with disabilities were very encouraging. Nonetheless, some participants gave accounts of challenges they encountered due to physical and attitudinal barriers that excluded full and enjoyable participation in the workplace. According to a participant:

They [colleagues] didn't tell me when there were meetings. I am in the monitoring department so we have to visit [travel around] and check things. They felt I couldn't do it. I was very annoyed and shouted, so now they [began to] invite me to all the meetings.

There were accounts of people with disabilities stereotyped into certain jobs. For instance, one participant stated that: "...large corporations tend to put blind people in call centers [regardless of their education and training]". Others participants opined that people with disabilities were sometimes employed as token gestures. According to one participant:

Some women [with disabilities] are given jobs just because of quotas. She just sat in the corner arranging papers. She doesn't have a job description. There might not even be a job description. She doesn't know what her job is all about. She is on the pay roll to give the impression that they are employing people with disabilities. [But] it is just a token employment.

The accounts of the participants indicated that women with disabilities might encounter additional problems in finding employment either because of the patriarchal society or because of the pressures on firms to present attractive images. According to one female participant: 
Men with disabilities will always find a job, but not a woman with a disability [regardless of her training]. Society will think she should be mother, she should be home-keeper and she should be at home.

Although some women with disabilities might possess extensive computer training and skills they might not be hired because as one participant put it:

Jobs like receptionist has a kind of public image. If they have said in the advert that only women need apply, they have in mind a certain kind of woman - a pretty face, an attractive face, a public relations model. Someone very attractive that people will admire.... Nobody will ever consider a woman with disability in that kind of job.

It might be the case, however, that other factors contributed to the lower employment opportunities for women. The level of education was mentioned by the participants as an important issue affecting employment opportunities. According to one female participant:

Disabled (sic) women are far less employed compared to men with disabilities. That could be tied to their education level. They don't go to school, so they are not educated to the required level, and so they don't get the jobs.

\subsection{Gender Inequalities and Unique Challenges of Women with Disabilities}

Some unique challenges countered by women with disabilities in the country in employment were mentioned in the foregoing section. Yet, the participants were unanimous that women with disabilities encounter more obstacles that could be attributed to gender inequalities in the country. According to the participants, women with disabilities in the country encountered unique challenges in various aspects of life that men with disabilities might not. One female participant stated that when she wanted to contest for the position of president of a national DPO, she encountered strong opposition from male members who felt only men should contest for that position. This participant lamented that the patriarchal structure of the Nigerian society discouraged women with disabilities from attempting to contest for leadership positions. According to the participants, among people with disabilities in the country, men were preferred to women when there were contests for leadership positions in DPOs due to the patriarchal system. Thus, women with disabilities in the country encounter multiple discrimination. One female participant stressed that:

Women with disabilities have a lot to contend with. We face (sic) a lot of different discrimination based on gender, because of the patriarchal society we live in. We also face (sic) discrimination because of our disability. We experience social discrimination which can either be based on being a woman or because we are disabled.

According to another participant, society's misconceptions of women with disabilities manifested in many spheres of life, including the medical profession. This comment from a female participant who worked with women with disabilities amply demonstrated the attitudinal barriers that these women encountered in accessing healthcare:

There's a woman [with a disability] who went for anti-natal examination. When she got to the clinic, the doctor said "What can I do for you?" The lady said, "I came for anti-natal examination." The doctor said, "Who did this to you? You don't feel sorry for yourself in your condition? You got pregnant?"... According to the medical doctor she already had problems she should not add pregnancy to them. He felt he could determine who could have a family and who should not, who should have relationships and who should not.

In addition, some female participants discussed the physical and sexual violence encountered by women with disabilities, and the reaction of society and the judicial system when they reported such abuses. According to one participant:

There was a case where a woman in a wheelchair was raped. The case was not taken seriously. Even the family members did not want us to pursue it. They felt that if a disabled woman got raped, she should have been grateful that someone wanted to have sex with her!

According to the participants, due to the patriarchal nature of the society, females with disabilities were less likely to be educated than their male counterparts. A female participant stated that when families expend money to educate their children in the country they considered it as an investment. They expected that when the children completed their studies they would be in the position to support the families; so that there would be a return on the investment. As one 
participant put it:

If you train up a boy, he will grow up and carry on the family name. A girl, however, will join another family [through marriage]. So the return on investment is less [on the female child].

The four female participants highlighted the multiple discrimination encountered by females with disabilities in attempting to access quality education. According to one of them:

Except in families where there is a lot of education [educated family members], most families think "What is the use [educating a female with a disability]? What can she do in her condition? Why should I invest much on someone who will just return home and not even go to work? What is the value in that? Why not learn something like hairdressing?" So they will deny her the rights of a good education.

It's clear from these accounts that females with disabilities in the country could encounter greater difficulties in accessing education and other services due to the patriarchal nature of the society.

\subsection{Barriers to Accessing Education}

The importance of education in ensuring people with disabilities acquired knowledge and skills that would enable them to develop their potentials and live productively was one theme repeatedly stressed by the participants. According to them, regardless of the specific disabilities, with quality education individuals with disabilities could live productive and contributing lives. As one participant put it: "I have education that opens doors for me". Interestingly, all the interviewees for this study had good educational background. Six of them had completed bachelor's degree programs and a few of them had graduate degrees. Nonetheless, they considered themselves privileged and not representative of the majority of individuals with disabilities in the country. They pointed out that the vast majority of individuals with disabilities in the country were not educated or had very little education. The participants provided ample examples of barriers encountered by people with disabilities in accessing education in the country. They repeatedly mentioned the lack of support services and special facilities for students with disabilities. Most of the participants attended regular educational programs in the country, especially for their bachelor's degrees. They indicated that the absence of support services and facilities created barriers to accessing education in inclusive settings in Nigeria. They lamented the plethora of physical barriers in the school that restricted access to classrooms and other facilities for wheelchair users and others with mobility challenges.

The participants were unanimous in stating that classrooms and lecture theatres in colleges and universities in the country were not accessible to wheelchair users. According to them, the facilities were designed with front stages or platforms very close to the entrances with steeped seating arrangements. Considerations were not made for wheelchair users. According to the accounts of the participants, in some institutions classrooms could be on the second or third floor of buildings. There were no elevators. This made it impossible for wheelchair users to access those classrooms. With formal support services unavailable, students with disabilities had to seek solutions to the challenges they encounter in attempting to access the classrooms and other facilities on their own. According to one of the participants: "I was told that I had to approach each lecturer and request them to move the lectures to the first floor [since I could not get to the upper floors on my wheelchair]".

Physical barriers to accessing accommodation in the dormitories were narrated by the participants. According to their accounts, the dormitories were not accessible to wheelchair users because there were no ramps, the entrances were too narrow, and the rooms were very tight and often over-crowded. According to the participants, some dormitories and dining halls were located far away from the classrooms. This created problems for those students who had difficulties walking long distances. As one of the participants described it, "The distance from the dormitory to the dining hall was very long. I could not keep going back to the dining room for each meal".

Further, the participants stated that facilities in the dormitories were not designed to ensure accessibility by people with disabilities. For instance, restrooms and bathrooms in the schools were virtually inaccessible to wheelchair users. One participant stated: "The toilets were so high, I couldn't climb (sic) them". Some participants stated that the dorms were so inaccessible that they decided to live at home with their families. Some stated that these accessibility issues limited their choice of schools. They had to choose schools that were driving distances from their homes. Commenting on her experience at school one interviewee remarked:

I think the hostels are not disability friendly. I tried the hostel for three months but found I couldn't cope, so I moved back home and went to school from there. 
According to the participants, the classrooms in many institutions of higher education in the country were located far away from the dormitories. Students must commute to and from by buses provided by the schools or take cabs. However, the buses were not wheelchair accessible, according to the participants. Another issue raised by the participants was that some schools segregate students with disabilities in the dormitories. Rather than taking actions to ensure all the dormitories were accessible, the administrators would designate a building for students with disabilities. Sadly, the designated building would not be accessible due to structural barriers, according to the participants. The participants suggested that the goal of the administrators was just to lump students with various disabilities together thereby making them invisible. As one participant explained it, "The disabled students were segregated. They had a block to themselves in the female hostel. To me it was another system of discrimination".

\subsection{Attitudinal Barriers Hindering Access to Education}

From the accounts of the participants, it appeared that at times barriers emerged when individuals with disabilities were applying for admission into schools, due to the negative attitudes of the school authorities. Such negative attitudes could be due to misunderstanding of the nature and needs of people with disabilities or due to blatant discrimination. The latter seemed to be the case for those with stigmatized conditions such as leprosy as the comment of one participant indicated:

There was a time I saw my name for entrance to School of Nursing, S.. (name supplied) I passed the examination, I passed the interview, but they refused to admit me because I am a person affected by leprosy.

The attitude of teachers and school administrators was a concern raised by the participants. It was not only when seeking admission into schools that these attitudinal barriers could be experienced, but also once in the schools. As one participant explained: "In the class nobody wanted to associate with me, I was separated at the back. I was separated even on the football field". According to the participants, some teachers were reluctant to make even the minimum adjustment to ensure access to lectures by students with disabilities. One participant who could not access the classroom due to mobility challenges lamented that: "One of the lecturers even said I should connect a loud speaker system so I could hear the lecture from outside".

However, one participant with hearing loss indicated while she had no interpreter in an inclusive classroom, the teacher encouraged using writing to ask questions and in communication. The teacher wrote responses and used writing to communicate. While this was commendable, most accounts provided by the participants were negative and clearly indicated that the attitude of the school authorities created barriers in the education of learners with disabilities in the schools.

Negative attitudes to attending schools by people with disabilities could emanate from the families. One participant narrated how the father was not supportive when she sought admission into college. He told her to forget attempting to attend college and instead to "..become a seamstress like your mother."

\subsection{Lack of Educational Personnel and Resources}

The participants expressed concerns about the lack of competent personnel and resources in the schools. According to them, these issues created further hindrances in accessing quality education for students with disabilities. For instance, in schools for deaf students, one of the participating DPO official claimed that "..the majority of deaf schools in the country do not have teachers who are qualified in the language of the deaf - sign language". One participant with hearing loss opined:

[The majority of] teachers of deaf children do not communicate with us in our own language..... This inability to communicate effectively with students impacted negatively on their cognitive and social skills development.

Further, one DPO official stated that although the government built many schools for deaf children, qualified personnel and the resources necessary for successful education of the students were lacking.

Participants with hearing loss advocated the recognition of sign language as an official language of communication in educational programs serving learners with hearing loss in the country. They argued that this would promote awareness of the importance of sign language in educating deaf students. Thus, the current communication barriers encountered by these students would be greatly reduced, if not eliminated entirely. According to one participant: 
If sign language is recognized, there is hope of it being accepted in many places, especially in schools. With it will come a law that mandates teachers to be fluent in sign language before they can be certified and employed as teachers of deaf children.

The participants also reported that learners with visual disabilities encountered communication barriers in the schools. Most schools in the country still extensively utilized chalkboard and word-processed handouts. These were not beneficial to blind students. According to the participants, there continued to exist acute shortages of learning materials in Braille or in audio formats. A blind participant narrated attending a special primary school for blind children. At this school he had access to all the equipment he needed and learned Braille at an early age. However, when he began postsecondary education he encountered difficulties. According to this participant:

The difficulty was collecting your books and getting your equipment. I had to depend on the handouts and notes given by the lecturers. My friends read them out to me [because there was no Braille or recording equipment].

\subsection{Public Information and Communication Barriers}

The participants expressed concerns that information and communication for the general public was often not accessible to individuals with disabilities. According to them, this created further barriers to individuals with disabilities in accessing services in the country. One of the participating DPOs official considered the lack of access to public information and communication as one of the biggest barriers encountered by its members. According to this DPO official, its members were often the last to receive information because of their hearing disability. The participant pointed out that: "...major television stations do not hire the services of sign language interpreters, and programs [with captions] for the Deaf are practically non-existent". This medium of public information, education, and communication was therefore not accessible to people with hearing loss in the country. According to one participant, at times of heightened tension such as terrorist attacks that were common in the country this posed concerns for their security and welfare. At such critical times, one participant stated:

All they write [in television news] is the headlines 'Curfew imposed in Abuja'. That is all - 'curfew imposed'. Why? When? Time? We do not get that. Just that curfew is imposed.

In addition, a deaf participant stated that there were very few training programs for sign language interpreters in the country. This meant that there was an acute shortage of qualified sign language interpreters in the country. According to participants, public service agencies such as hospitals and schools did not provide interpreters for deaf clients. Deaf people must arrange for an interpreter to attend, for example, an appointment with a hospital. According to one participating DPO official:

\footnotetext{
When deaf people go to hospital, they cannot afford sign language interpreters, and the government does not provide this service. This means that communicating with healthcare providers is a major challenge. Many deaf people end up not going to hospitals because of language barrier.
}

According to the participants, people with visual disabilities in the country encountered tremendous barriers in accessing public information or communication that was in print form. According to them, very little, if any essential public information or communication was made available in large print, Braille, or audio-format. One participant lamented that people with visual disabilities, "....need [public] information in Braille, and if not in Braille then in audio. At the moment we don't have anybody developing audio information".

\section{Implications and Conclusion}

Some of the disabling barriers in accessing services encountered by people with disabilities in Nigeria have been highlighted by the data from this study. Clearly, people with disabilities in the country encountered a litany of barriers in attempting to access various services. Despite the small sample size, the themes raised by the responses of the participants regarding the barriers to accessing services were similar and consistent. The findings of this study, although quite depressing in some areas, hold several implications regarding strategies for removing the disabling barriers and enhancing access to services by people with disabilities in the country.

One of the significant findings of this study was that despite over a decade of lobbying by people with disabilities 
in Nigeria, there existed no mandatory legislation at national level protecting their rights to access services. The absence of a legislation guaranteeing their human rights is a prominent barrier to accessing services. This barrier must be removed by the enactment and implementation of a disability legislation at the national level. Evidence is consistent that legislation is critically important in upholding the rights of people with disabilities to access services (Eleweke, 2013, Obiakor \& Eleweke, 2014). Without a legal framework, there is no foundation for people with disabilities to stand and demand their rights to access services.

The DPOs in the country must intensify their advocacy efforts to put pressure on the government to enact and implement the Disability Bill. In order to achieve this goal, they must be united and coordinate their advocacy activities and strategies. Using the mass media (print, electronic, and social) these organizations, collaborating harmoniously will exert sufficient pressure on the government to enact and implement that legislation. Further, the DPOs in the country should be more active in conducting public awareness campaigns. These campaigns are necessary to (a) promote public awareness of the potentials of people with disabilities, (b) bring their needs and challenges to public attention, and (c) greatly reduce or eliminate negative attitudes and discrimination that hinder these people from accessing services.

Further, the DPOs in the country must advocate for the establishment of a presidential commission on disabilities that will be reporting directly to the president. The activities of this commission will ensure that the needs of people with disabilities are among the nation's top priorities. The commission will oversee the implementation of the disability legislation once enacted. Presently, the Federal Ministry of Women Affairs and Social Development (FMWASD) is responsible for disability issues in the county. It's apparent that this arrangement is not effective in addressing the disabling barriers encountered by people with disabilities in the country. It is therefore suggested that Ministries of Disability and Rehabilitation (MDR) should be established at all levels of government (federal, state, and local). This will ensure that issues affecting people with disabilities will receive important consideration in policy formulation and implementation. For instance, the MDR will have its own budget for implementing programs aimed at eliminating barriers encountered by people with disabilities. Further, the MDR will have the resources to embark on massive public awareness campaigns aimed at promoting awareness on disability issues.

For improvements to occur in the provision and access to various educational and related services by Nigerians with disabilities, it is very important that educational and related programs should have adequate staff, facilities and resources. This will ensure that all learners with or without disabilities are able to access meaningful and appropriate education in inclusive settings. There are companies or firms in the country that can produce the necessary educational materials. The government should provide incentives such as lower taxes or lands to expand factories for the production of the needed materials. This will ensure that all educational programs in the country are adequately equipped to satisfactorily cater for all learners.

Given the ever-increasing population of the country, more programs should be established for the training of teachers and related support staff such as sign language interpreters, braille specialists, producers of audio materials for the blind, guidance counselors, psychologists, educational audiologists, speech and language therapists, and mobility support specialists. To achieve this goal, more colleges and universities in the country should be mandated to establish departments for these training programs.

Considering that more individuals with disabilities attend schools in inclusive settings and that some of educated adults with disabilities may be working in the various regular educational programs as teachers, instructors, or staff in administration and management, it is essential to set up Disability Support and Resource Centers (DSRCs) in all the educational programs and at all levels - K-University. The DSRC should be an important mandate in the disability legislation that should be enacted and implemented. The DRSC will be charged with ensuring that all relevant support services such as interpreters and note takers for the deaf, braille specialists and audio material producers for the blind, and mobility support staff for the physically challenged to ensure success in their education and jobs.

In conclusion, we believe progress in improving access to various services for Nigerians with disabilities is possible if the government enacts the disability legislation that has been in the works since 1999. Each state of the federation should thereafter be mandated to take actions that will ensure full implementation of the law. Further, a presidential commission should be set up to ensure full implementation of the disability legislation. Reporting directly to the President of the Republic, the Commission will ensure compliance and implementation of the provisions of the disability legislation. Clearly, the current arrangement whereby disability issues are handled by the Ministry of Women Affairs and Social Development is not effective. It seems to be the case, according to Obiakor and Eleweke (2014), that disability issues are not considered important. Consequently, very little funding is provided to improve services. Thus, the enactment and full implementation of a national disability legislation and consideration of all other strategies we have advocated will enhance access to various services by Nigerians with disabilities. With improved ability to access all 
essential services, they will be able to develop their talents and skills and contribute their quota to national and global developments.

\section{References}

Adelaja, A. (2009). Providing equal opportunities for persons with disabilities'. Retrieved from: http://234next.com/csp/cms/sites/Next/ News/Metro/5467817147/Providing_equal_opportunities_for_persons_with.csp

Barnes, C. (1992). Qualitative research: Valuable or irrelevant? Disability, Handicap and Society, 7(2); 115-124.

Barnes, C. \& Mercer, G. (2004). Theorizing and researching disability from a social model perspective.

In C. Barnes \& G. Mercer (Eds.) Implementing the social model of disability: Theory and research, pp 1-17. Leeds, UK: The Disability Press,

Blaikie, N. (2000). Designing social research. Cambridge, UK: Polity Press.

CBR Africa Network (CAN). (2011). Conferences. Retrieved from: http://www.afri-can.org/conferences.html

Charmaz, K. (2001). Qualitative interviewing and grounded theory analysis. In J. Gubrium, \& J. A.

Holstein (Eds.) Handbook of Interview Research. Thousand Oaks, CA: Sage

Creswell, J. (2012). Educational research: Planning, conducting, and evaluating quantitative and qualitative research (4th ed.). Boston, MA: Pearson.

Department for International Development (DFID). (2000) Disability, poverty and development. London, UK: Author.

Disability Rights Education and Defense Fund (DREDF) (2011). Nigerians with Disability Decree, 1993. Retrieved from: http://www.dredf.org/international/nig1.html

Eleweke, C. J. (2013). A review of the challenges of achieving the goals of the African Plan of Action for people with disabilities in Nigeria. Disability \& Society, 28(3); $313-323$.

Index Mundi (2011). Nigeria population. Retrieved from: http://www.indexmundi.com/nigeria/population.html

Obiakor, F. E., \& Eleweke, C. J. (2014). Special education in Nigeria today. In: A. Rotatori, J. Bakken, F. Obiakor, \& U. Sharma: Advances in special education: International perspectives, 28; 379-397. London, England: Emerald.

Ogala, E. (2009). Nigeria's senate passes disability bill. Retrieved from: http://234next.com/csp/cms/sites/Next/News/National/5388085147/story.csp

Oliver, M. (1990). The politics of disablement. London, UK: Macmillan

Oliver, M. (2004). "If I had a hammer: The social model in action". In J. Swain, S. French, C. Barnes, \& \& C. Thomas (Eds.) Disabling barriers - Enabling environments, pp. 7-12, London, UK: Sage/Open University.

Shakespeare, T. \& Watson, N. (2002). The social model of disability: An outdated ideology? Research in Social Science and Disability, 2(1); $9-28$.

Smith, N. (2007). The face of disability in Nigeria: A disability survey in Kogi and Niger States. Unpublished MSc Dissertation, Melbourne University, Australia.

Smith, N. (2011) 'The Face of Disability In Nigeria: A Disability Survey in Kogi and Niger States'. Disability, CBR and Inclusive Development, 22(1); 35-47.

Swain J. \& French S. (2004). Researching together: A participatory approach. In S. French \& J. Sim (Eds.) Physiotherapy: A psychosocial approach (3rd ed.). Oxford, UK: Butterworth- Heinemann.

Union of the Physically Impaired Against Segregation (UPIAS). (1976). Fundamental principles of disability. London, UK: Author

United Nations (UN). (2010). Including the rights of person with disabilities in United Nations programing at country level: A guidance note for United Nations country teams and implementing partners. New York: United Nations Development Group/Inter-Agency Support Group for the CRPD Task Team.

United Nations (2011a). Convention and optional protocol signatures and ratifications. Retrieved from: http://www.un.org/disabilities/ countries. asp?navid=12andpid=166

United Nations (2011b). Convention on the rights of persons with disabilities Retrieved from: http://www.un.org/disabilities/ default.asp?navid=13andpid $=150$

World Health Organization (WHO) \& World Bank (2011). World Report on Disability. Geneva, Switzerland: World Health Organization. 
